\title{
COMPARISON OF TOTAL PRESSURE FLUCTUATIONS IN STEAM TURBINE STAGES WITH DIFFERENT DEGREE OF REACTION
}

\author{
Tomáš JelíneK ${ }^{a, *}$, MARTin NĚMEC $^{a}$, Petr MilČÁK $^{b}$ \\ ${ }^{a}$ Czech Aerospace Research Centre, Beranových 130, Prague 9, Czech Republic \\ ${ }^{b}$ Doosan Škoda Power, Tylova 1/57, Pilsen, Czech Republic \\ * corresponding author: jelinek@vzlu.cz
}

ABstract. The contribution deals with analysis of unsteady pressure measurement in one and half axial turbine stages. The measurement was performed in VZLU air test turbine. Two stages geometries with different degree of reaction were tested in this work. Comparison of unsteady flow field behaviours is discussed.

KEYwORDS: Turbine stage, stator-rotor interaction, driving forces.

\section{INTRODUCTION}

A multistage arrangement design of turbines is more and more complex and it is necessary to combine aerodynamic and strength aspects. This evolution of design procedures is followed also in a long-term cooperation of VZLU with the leading producer of steam turbines Doosan Škoda Power (DSPW).

Blades excitation is strongly affected by axial gap, blade count ratio and overall design of the stage. Combined effect of the axial gap and blade count ratio was deeply studied by Chen et al. in [1. Their results show resonance effect of stator and rotor row for huge number of combinations of blade count ratios and axial gaps. The resonance effect is caused by interaction of the rotor potential field with the stator outlet flow field. Moreover, in the case of a multistage turbine, the interstage interaction and clocking effect influences the flow field development what presented Reinmöller at al. in [2] and Porreca at al. in [3]. A sensitivity of stage geometry on the excitation is presented by Gao et al. in 4], where decrease of stimulus was achieved by using a negative bowed stator geometry. Many other works are focused on optimization of the stage geometry. Such studies are performed with help of numerical simulations and usually it is necessary to use scaling a number of blades to reduce computational costs. This could generate a fairly large discrepancy as showed Clark in [5].

This work is unique because of two degrees of reaction and various stator aspect ratios were experimentally investigated on one and half stage configuration. Experimentally obtained unsteady flow field parameters were analyzed and comparison of the stimulus behaviours of novel steam turbine stage design was performed. Driving forces were not determined, but only pressure fluctuations were computed from unsteady flow field parameters measurements. This approach is sufficient for the comparison of various cases. A reaction stage and a stage with increased reaction

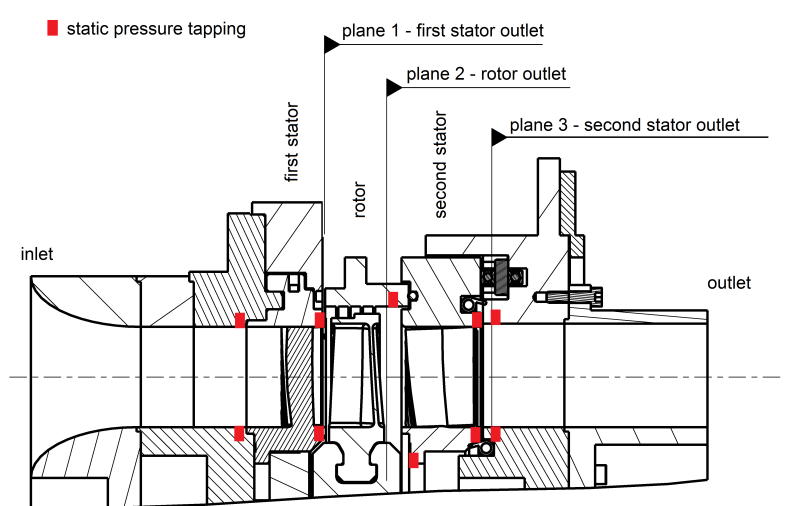

Figure 1. The one and half stage cofiguration of the test rubine.

(marked as REAC and IR, respectively) were studied in nominal and off-design regimes. The experiments caught unsteady flow field behaviours at the outlet of the rotor and also at the outlet of the second stator. An influence of degree of reaction in combination with stator aspect ratio and rotor rotational speed is studied in this work.

\section{Test turbine CONFiguration}

The experimental work was performed in VZLU in the axial turbine stage test rig. The rig was adapted to the one and half turbine stage to study the multistage flow structures [6. The one and half stage facility is depicted in Fig. 11 The configurations of tested stages are characterized in Tab. 1. An axial gap ratio (GR) and a vane/blade count ratio (BCR) are important parameters in stimulus point of view, therefore these parameters are also included in this table.

Detailed flow field investigation was performed by a miniature five-hole pressure probes (tip diameter 1.2 $\mathrm{mm}$ ) and with a fast response pressure probes (FRPP) developed in VZLU [7]. 


\begin{tabular}{lcc}
\hline & REAC v2-1 \& v2-2 & IR v1-2 \& v1-2 \\
\hline Stator aspect ratio - 1st / 2nd & $2.0 / 1.1$ & $1.0 / 1.0$ \\
Rotor aspect ratio & 1.71 & 1.94 \\
Stage isentropic Mach number & 0.30 & 0.40 \\
Mid-span reaction & 0.43 & 0.12 \\
Optimum velocity ratio u/cis & 0.65 & 0.55 \\
Midspan gap ratio - plane 1 / 2 & $0.23 / 0.67$ & $0.11 / 0.63$ \\
Blade count ratio - plane 1 / 2 & $0.61 / 1.09$ & $0.53 / 1.88$ \\
\hline
\end{tabular}

TABLE 1 . The turbine stage geometry and operational regime parameters.

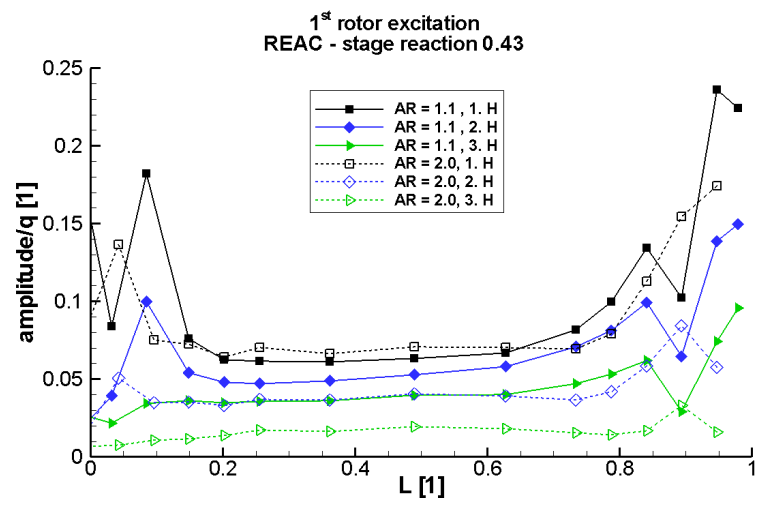

(A) . REAC stage.

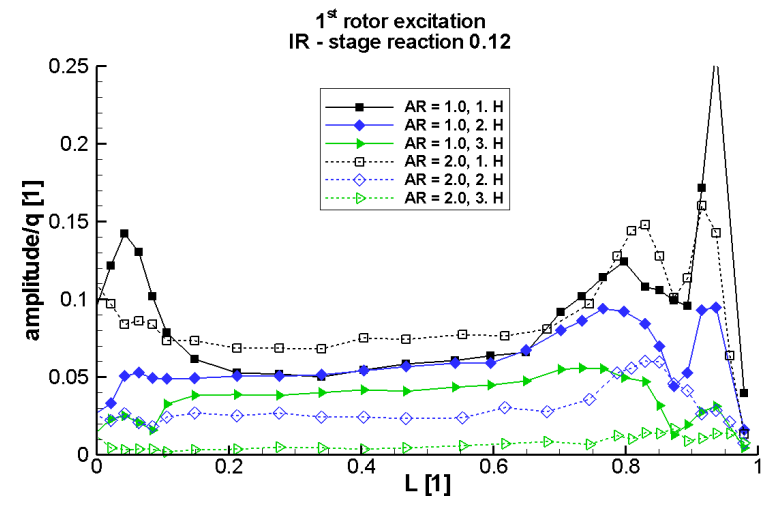

(B). IR stage.

FiguRE 2. The first rotor excitation for two stator aspect ratios.

\section{THE FIRST STATOR EXCITATION}

The first stator is specified by uniform inlet flow in this test turbine configuration, so the excitation of vanes is caused only due to rotor potential field. It is shown in [1, that the worst case occurs for BCR approximately 0.7 , where the resonance appears. The BCR is sufficiently far from the resonance in this case. The excitation by the rotor potential field is captured in the case of the IR stage also by the fast response pressure probe placed in the plane 1 , see Fig. 1. Measured amplitude is very low what is consistent with BCR value 0.53. Radial distribution of the absolute total pressure amplitude is shown in Fig. 4b. The absolute value of the amplitude is approximately four times lower compared to the rotor excitation, that is in agreement with [1]. Influence of the rotational speed on the excitation of the first stator is shown in Fig. 6a.

\section{THE FIRST ROTOR EXCITATION}

The first rotor excitation is mainly caused by passing the first stator wakes. The excitation of four cases is shown in following graphs - Fig. 2a and Fig. 2b. These graphs show comparison of two stator families and two aspect ratios for each family. High aspect ratio stator geometry is characterised by a stronger decrease of the amplitude with increasing degree of harmonic component. Low aspect ratio stator has a very similar excitation for three harmonics in the midspan region. The highest excitation is captured in secondary flow regions.

\section{THE SECOND STATOR EXCITATION}

The excitation of the second stator is caused by rotor wakes at the inlet of the stator. The relative pressure fluctuations are the highest in turbine stage (shown in Fig. $5 \mathrm{a}$ and Fig. 5b). Nevertheless, the second stator excitation in absolute values point of view is approximately three times lower compared to the rotor excitation - radial distribution is shown in Fig. 4a and Fig. 4b-amplitude scale is kept the same in both graphs. The excitation of the second stator at the outlet caused by the first rotor wakes is slightly lower compared to the inlet excitation. As the second rotor is not present in this configuration, there is no excitation by second rotor potential field, which could cause additional stator excitation. The second stator excitation is moreover dependent on the clocking with the first stator. Clocking effects are discussed in [8] for the case of the REAC stage.

\section{THE SECOND ROTOR EXCITATION}

Although the second rotor was not present in the test turbine, the excitation of the second stage rotor can be obtained from the second stator time averaged outlet flow field. Radial distribution of the rotor excitation is shown in Fig. 3a (relative values) and in Fig. 3b (absolute values). Both second stator geometries had 


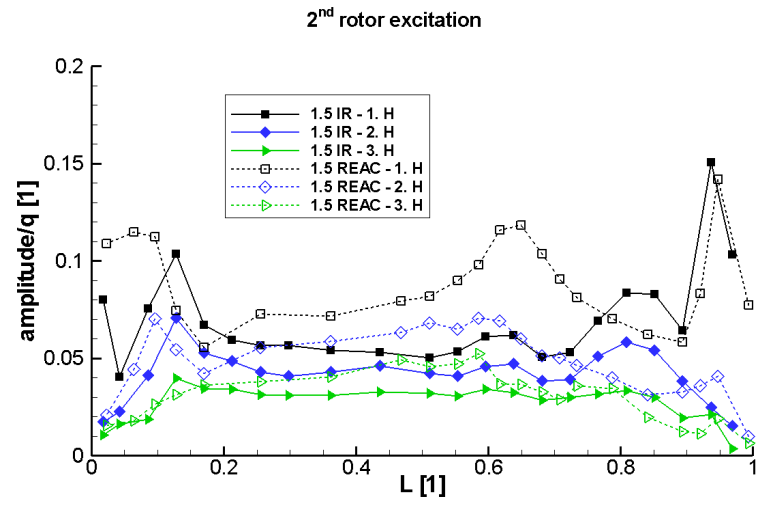

(A) relative total pressure amplitudes.

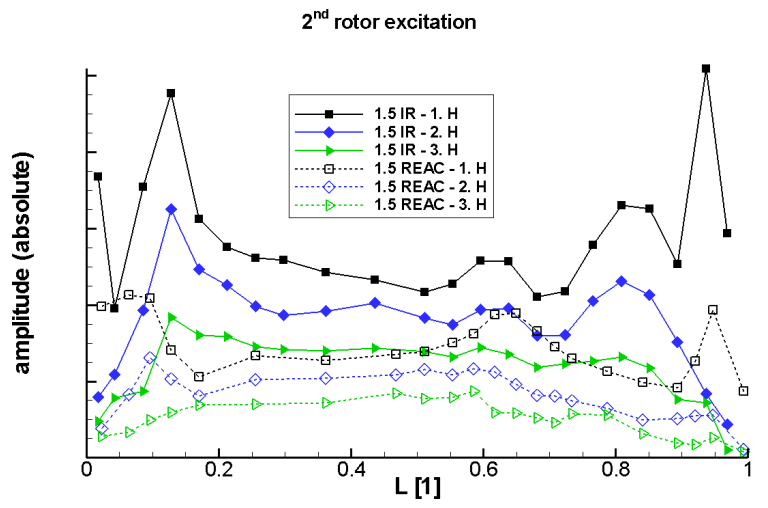

(B) . absolute total pressure amplitudes.

Figure 3. The second rotor excitation - REAC and IR stage.

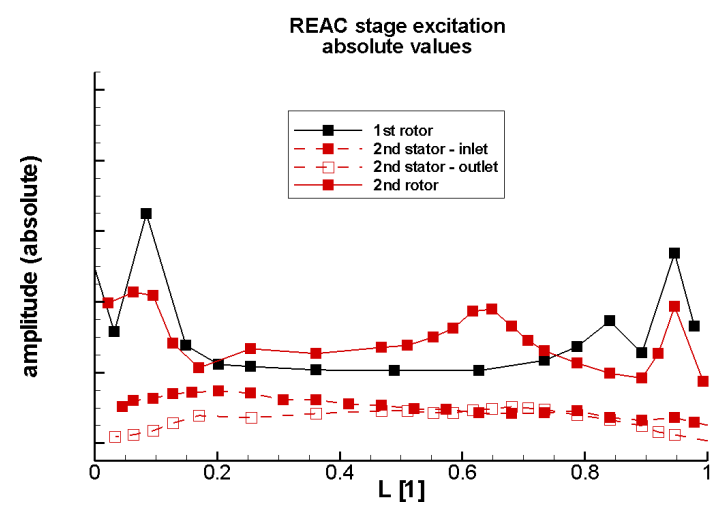

(A) . REAC stage.

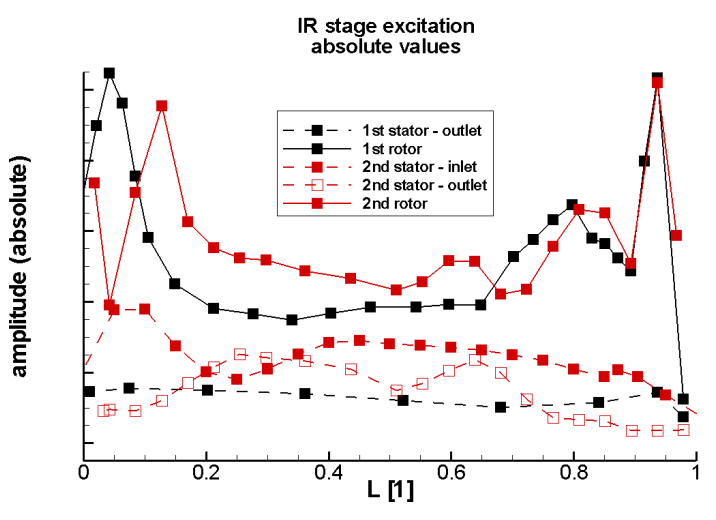

(B). IR stage.

FiguRE 4. Absolute total pressure amplitudes.

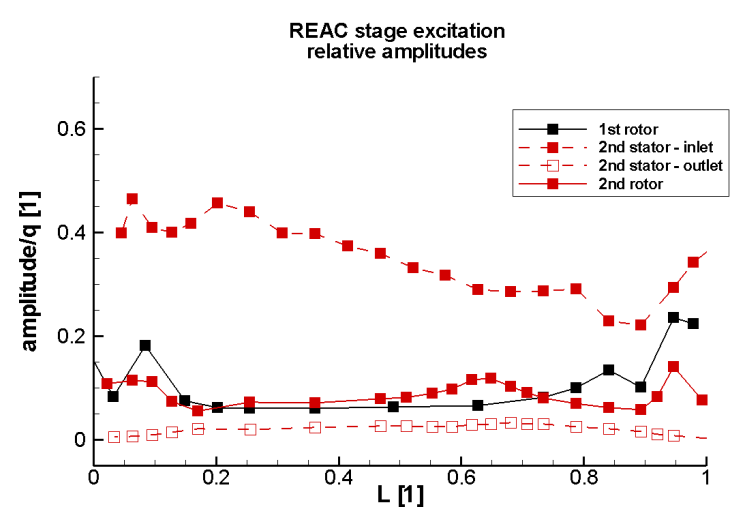

(A) . REAC stage.

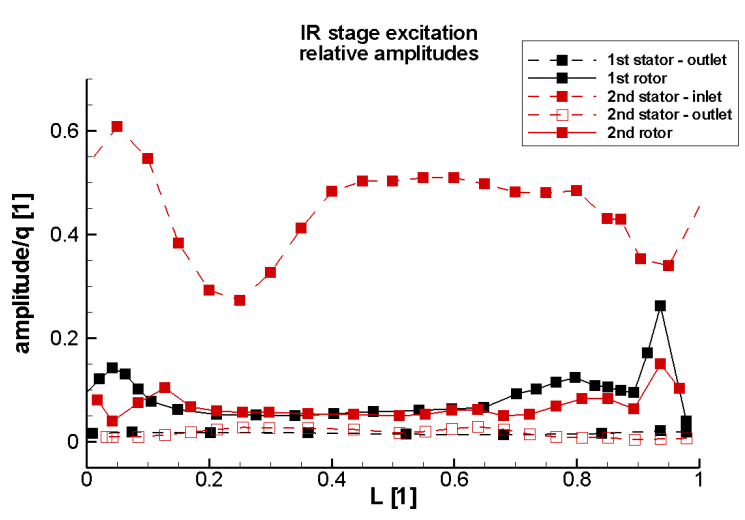

(в) . IR stage.

FIGURE 5. Relative total pressure amplitudes. 


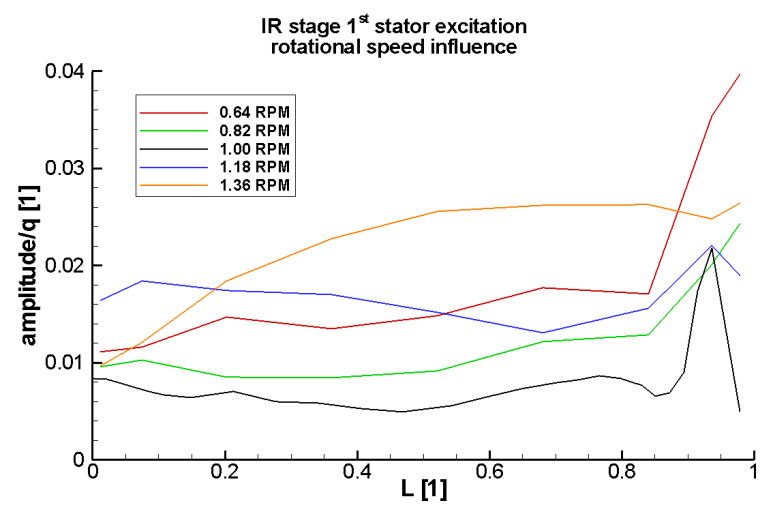

(A) . The first stator of IR stage.

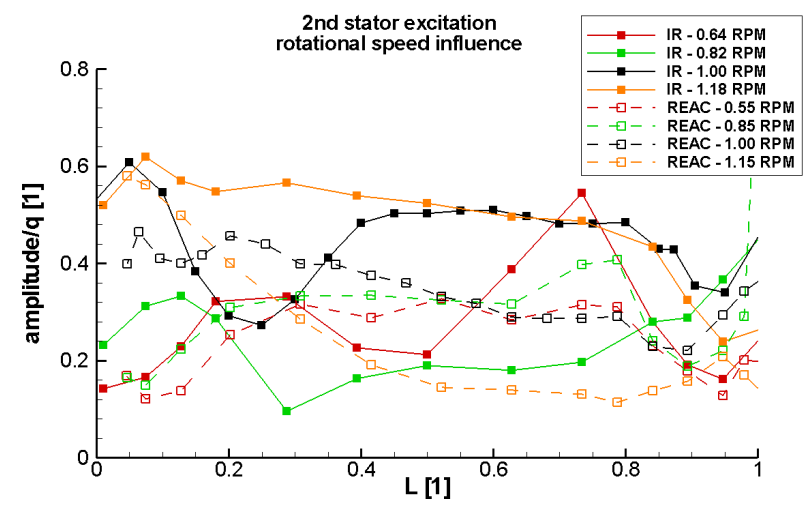

(B). The second stator of IR and REAC stage.

Figure 6. Influence of rotational speed on stators excitation.

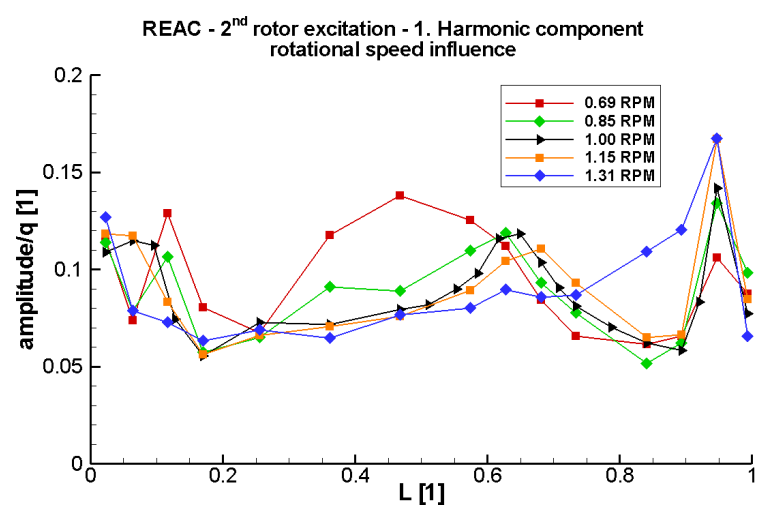

(A) . REAC stage.

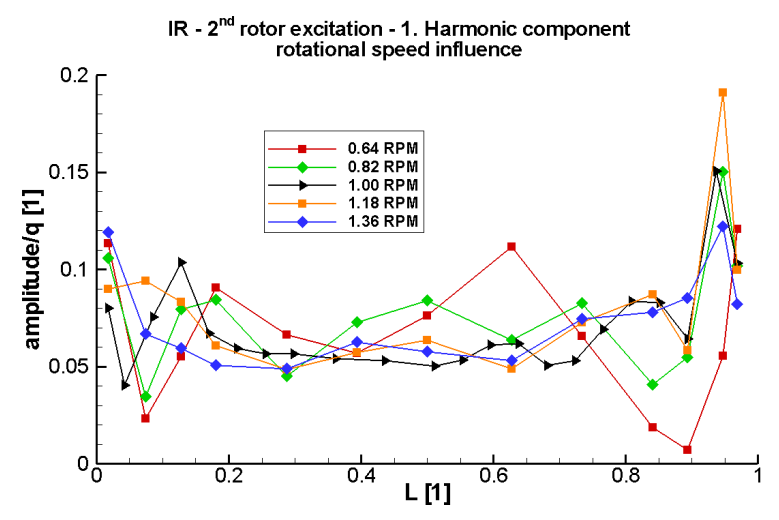

(B) . IR stage.

FIGURE 7. The second rotor excitation - influence of rotational speed.

low aspect ratio, so a decrease of the amplitude with increase of harmonic component was less significant.

\section{THE ROTOR ROTATIONAL SPEED INFLUENCE}

The rotational speed strongly influences the flow filed in the turbine stage. As a blade incidence angle is changed, separation regions may occur, radial distribution of velocity is affected and thus unsteady flow field behaviours are changed. The potential field of the rotor is also slightly affected by the rotational speed, so the excitation of the first stator is also changed, as it is shown in Fig. 6a

As it was said, the first rotor is excited due to its interaction with first stator wakes. The most important for the rotor excitation is time averaged distribution of the pressure at the stator outlet. The time averaged first stator pressure distribution is not seriously affected by the rotational speed, thus the excitation of the rotor is also not changed.

The second stator excitation by the rotor outlet flow field is shown in Fig. 6b. The variation of the excitation in radial distribution is clearly visible in this figure, namely for the IR stage. A lower expansion in the case of the IR stage causes a higher influences of the rotational speed on the second stator excitation.
The highest excitation of the second stator is captured for nominal regimes.

The second rotor excitation radial distribution with the rotational speed influence is shown in Fig. 7a and Fig. $7 \mathrm{~b}$ for both stages. The radial distribution of the excitation is influenced more in the case of REAC stage. Extremely overloaded stage has a region of high excitation in the midspan. This effect is not as strong in the case of the IR stage, which is specified by more intensive expansion in the stator.

\section{Conclusion}

The excitation of one and half stages was studied for two degrees of reaction in wide range of regimes. The comparison of excitation results of stages with two degrees of reaction shown excitation insensitivity in the relative point of view. Absolute values of excitation are of course higher in the case of lower reaction stage, because of higher dynamic pressure, which is used for the normalization.

The first and the second rotor relative excitation stays nearly the same. This statement is valid for average excitation, because distribution of the excitation along blade height is strongly affected by the second stator secondary flow development. The second stator is strongly affected by the interaction with 
rotor tip leakage flow field. In the case of off-design regimes, the secondary flow development is affected by a change of the second stator incidence angle. The second rotor absolute amplitudes are slightly higher compared to the first rotor. This is caused by a higher outlet Mach number of the second stator compared to the first one.

Stator aspect ratio can influence damping of the excitation of higher harmonic components. It was tested in the case of the first rotor.

Excitation of the stator by the rotor potential field was also discussed and tested in the case of lower reaction stage. The results show that the excitation is the weakest in the nominal regime and grows with deviation from the nominal regime. The excitation caused by the potential field is generally weak for the cases where resonance does not occur.

\section{LIST OF SYMBOLS}

cis isentropic stage velocity $[\mathrm{m} / \mathrm{s}]$

$L$ nondimensional blade height [1]

$q$ dynamic pressure $[\mathrm{Pa}]$

$u$ rotor circumferential velocity $[\mathrm{m} / \mathrm{s}]$

$A R$ Aspect Ratio

$B C R$ Blade Count Ratio

$D S P W$ Doosan Škoda Power

FRPP Fast Response Pressure Probe

$G R$ Axial Gap Ratio

$H$ Harmonic component

$I R$ Increased reaction stage

$R E A C$ Reaction stage

$R P M$ Nominal rotor rotational speed

\section{ACKNOWLEDGEMENTS}

The work was done with financial support of the Technology Agency of the Czech Republic on the project TA04020129 "Investigation of flows in a multi-stage axial turbine stages arrangement".

\section{REFERENCES}

[1] T. Chen, K. Patel, P. Millington. Combined effects of both axial gap and blade count ratio on the unsteady forces of a steam turbine stage. ASME Paper No. GT2012-68874.

[2] U. Reinmöller, B. Stephan, S. Schmidt, N. R. Clocking effects in a 1.5 stage axial turbine - steady and unsteady experimental investigations supported by numerical simulations. ASME Paper No. 2001-GT-0304.

[3] L. Porreca, A. I. Kalfas, R. S. Abhari. Interstage flow interactions and loss generation in a two-stage shrouded axial turbine. Journal of Turbomachinery 131(January), 2009.

[4] K. Gao, T. Lin, Z. Xie, D. Zhang. Investigation on unsteady flow of a turbine stage with negative bowed stator. International Journal of Energy and Power Engineering 11(4), 2017.

[5] J. P. Clark, G. M. Stetson, S. S. Magge, et al. The effect of airfoil scaling on the predicted unsteady loading on the blade of a 1 and $1 / 2$ stage transonic turbine and a comparison with experimental results. ASME Paper No. 2000-GT-0446.

[6] M. Nemec, T. Jelinek, P. Milcak. An investigation of a flow field in a one and half axial turbine stage. AIP Conference Proceedings 1889(020025), 2017.

[7] M. Nemec. Development of fast response pressure probe for turbomachinery applications (in czech). PSE 2009, Pilsen, 2009.

[8] M. Nemec, T. Jelinek, P. Milcak. Clocking of stators in one and half stage of axial steam turbine. EPJ Web of Conferences 180(02071), 2018. 